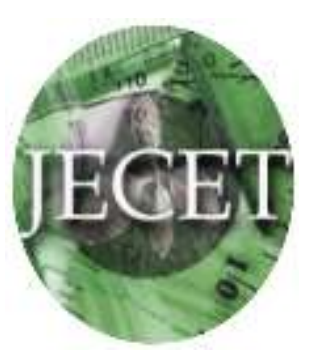

Research Article

\section{Juurnal of Enviranmental Science, Camputer Science and Engineering \& Technology}

\author{
An International Peer Review E-3 Journal of Sciences and Technology \\ Available online at www.jecet.org \\ Section C: Engineering \& Technology
}

\title{
Effects of Pre-injection Ratio on GCI Combustion Concept with Double Injections Strategy
}

\author{
Shouke Jia, Leilei Liu, Zhifa Zhang, Yue Liang, Jingyu Gong, Binbin Yang* \\ School of Transportation and Vehicle Engineering, Shandong University of Technology, \\ Zibo 255000, China
}

Received: 10 March 2021; Revised: 18 March 2021; Accepted: 30 March 2021

\begin{abstract}
In this paper, the influence of double injection strategy on combustion and emissions of gasoline compression ignition (GCI) has been analyzed, in order to solve the problem of poor performance under low load conditions. The engine model is established through CONVERGE software, and the simulation research on injection parameters, such as the pre-injection timing, the pre-injection ratio were carried out with an internal exhaust gas recirculation (EGR) rate of $40 \%$. Results show that higher thermal efficiency and lower emissions can be achieved when the pre-injection ratio reaches $60 \%$. As the pre-injection timing advances, the optimized pre-injection ratio is gradually increased. With the increase of the pre-injection ratio, the combustion duration gradually shortens and the indicated mean effective pressure (IMEP) shows an upward trend. Therefore, a reasonable mixture in the cylinder can be organized by the double injection strategy, thereby, achieving clean and efficient combustion under low load conditions.
\end{abstract}

Keywords: gasoline compression ignition; pre-injection ratio; double injection strategy; low load condition; combustion and emissions 


\section{INTRODUCTION}

As one of the greatest inventions of modern industrial development in the past two centuries, the internal combustion engine has been widely used in transportation, military and national defense construction, industrial and agricultural production and other fields due to its high thermal efficiency and high reliability. However, with the rapid development of the internal combustion engine industry, problems such as the shortage of traditional fossil fuels and combustion emission pollution have become increasingly prominent ${ }^{[1]}$. In recent years, in order to achieve the purpose of energy saving and emission reduction, internal combustion engine researchers have developed a series of combustion methods based on "Homogeneous Compression Ignition, Low Temperature Combustion"[2]. The current mature applications mainly include Homogeneous Charge Compression Ignition (HCCI) ${ }^{[3]}$, Premixed Charge Compression Ignition (PCCI) ${ }^{[4]}$, Reaction Controlled Compression Ignition (RCCI) ${ }^{[5]}$, and Gasoline Compression Ignition $(\mathrm{GCI})^{[6]}$.

In the exploration of achieving high efficiency and clean combustion of internal combustion engines, it is found that CI engines can obtain higher thermal efficiency and power output due to their high compression ratios, but have higher emissions of $\mathrm{NO}_{\mathrm{X}}$ and soot ${ }^{[7-10]}$. The SI engine can obtain lower $\mathrm{NO}_{\mathrm{X}}$ and soot emissions, but the power performance is relatively poor. Kalghatgi et al. ${ }^{[1]}$ proposed the concept of gasoline Partial Premixed Combustion (PPC), that is, Gasoline Compression Ignition combustion concept. After that, many researchers ${ }^{[12-15]}$ conducted in-depth research on the GCI combustion method through bench tests, numerical simulations, and laser research, and found that it can achieve an indicated thermal efficiency of up to 57\%, which proves that the GCI combustion method can expand the load limit while improving thermal efficiency, and has the potential to significantly reduce $\mathrm{NO}_{\mathrm{X}}$ and soot emissions.

Fuel injection strategy is one of the important technical means to improve the performance of GCI internal combustion engine. The quality of the mixture mainly depends on the gas flow state in the cylinder and the fuel injection strategy. The fuel injection time, pressure, and mass all affect the quality of the mixture in the cylinder. At present, the method of flexibly adjusting the fuel injection strategy to organize a reasonable mixture in the cylinder to improve the combustion has attracted the attention of a large number of researchers all over the world. Fang et al. ${ }^{[16]}$ studied the spray and combustion characteristics of preprimary injection under the double injection strategy.

The research shows that compared with single injection, the ignition position of the main injection is closer to the nozzle and the ignition delay period and, flame lift-off length are shorter under the action of the pre-injection of the two injections. As the time interval between pre-injection and main injection increases, the spray cone angle of the main injection decreases and the ignition delay period increases, but there is no significant difference in ignition position. Liu et al. ${ }^{[17]}$ explored the effect of different premixing ratios on the GCI stagnation period, and believed that a higher premixing ratio and earlier injection timing can help to prolong the ignition delay, but will lead to a fast combustion rate.

In order to control the pressure rise rate, the injection time should be kept no earlier than $-80^{\circ} \mathrm{CA}$ aTDC, and the premixing ratio should be less than $50 \%$. Zheng et al. ${ }^{[18]}$ conducted a GCI test study on a single cylinder test internal combustion engine modified from a 6 cylinder heavy duty diesel engine, and studied the effect of two injections on combustion and emissions in GCI mode under higher load. The results show that although the smaller two-injection interval has relatively high soot emissions, it is more conducive to shortening the ignition delay of the main injection, reducing the premixing heat release rate 
of the main injection and controlling the pressure rise rate; Although increasing the pre-injection ratio will lead to higher $\mathrm{HC}$ and $\mathrm{CO}$ emissions, lower $\mathrm{NO}_{\mathrm{X}}$ and soot emissions can be obtained, and the maximum pressure rise rate can be significantly reduced. The above research results show that selecting a reasonable injection strategy can achieve the purpose of improving GCI combustion performance. However, the current research on fuel injection strategy for GCI is mostly focused on medium and high load versus low load conditions. This paper will study the influence of double injections on GCI combustion mode under GCI low load conditions.

\section{RESEARCH METHODS AND MODEL ESTABLISHMENT}

In this paper, CONVERGE CFD software is used to study the influence of double injections strategy on GCI low load condition. CONVERGE is currently one of the most widely used software for CFD simulation research of internal combustion engines. It can perform detailed analysis and solution to the flow process and combustion process in the cylinder. The calculation models involved in this article mainly include: (1) RNG k- $\varepsilon$ turbulence model; (2) Euler-Lagrange spray model; (3) KH-RT breakup model; (4) Rebound/slide spray-wall model; (5) O'Rourke turbulent diffusion model; (6) Detailed chemical solver SAGE. The cross-section of the engine calculation grid and related parameters are shown in Fig.1 and Tab.1. The side length of the basic grid is $4 \mathrm{~mm}$, and the minimum side length of the encrypted grid is $0.3 \mathrm{~mm}$. The maximum number of grids is about 120,000 in top dead center.

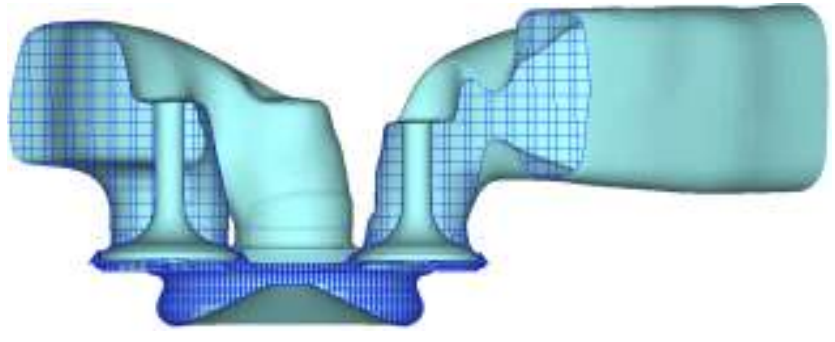

Fig.1: The cross-section of the engine calculation grid

Tab. 1: Values of various parameters of simulation and test comparison working conditions

\begin{tabular}{cc}
\hline Parameter & Value \\
\hline Engine speed $[\mathrm{r} / \mathrm{min}]$ & 1500 \\
Intake valve open $\left[{ }^{\circ} \mathrm{CA}\right.$ aTDC $]$ & -377 \\
Intake Valve Close $\left[{ }^{\circ} \mathrm{CA}\right.$ aTDC] & -133 \\
Exhaust valve open $\left[{ }^{\circ} \mathrm{CA}\right.$ aTDC $]$ & 125 \\
Total injected fuel mass $[\mathrm{mg} / \mathrm{cycle}]$ & 28 \\
Injection timing $\left[{ }^{\circ} \mathrm{CA}\right.$ aTDC $]$ & -20 \\
Intake presser $[\mathrm{MPa}]$ & 0.15 \\
Inlet temperature $[\mathrm{K}]$ & 323 \\
\hline
\end{tabular}


Fig.2 is the comparison of cylinder pressure heat release rate between numerical simulation and test. By comparing the two results, it can be seen that the calculated results are in good agreement with the actual test results. Therefore, this study believes that the sub-models used in the numerical simulation process are reasonable, which can reflect the actual working state of the test engine more truly and reliably. The availability of the model is high, and this model can be used for subsequent research.

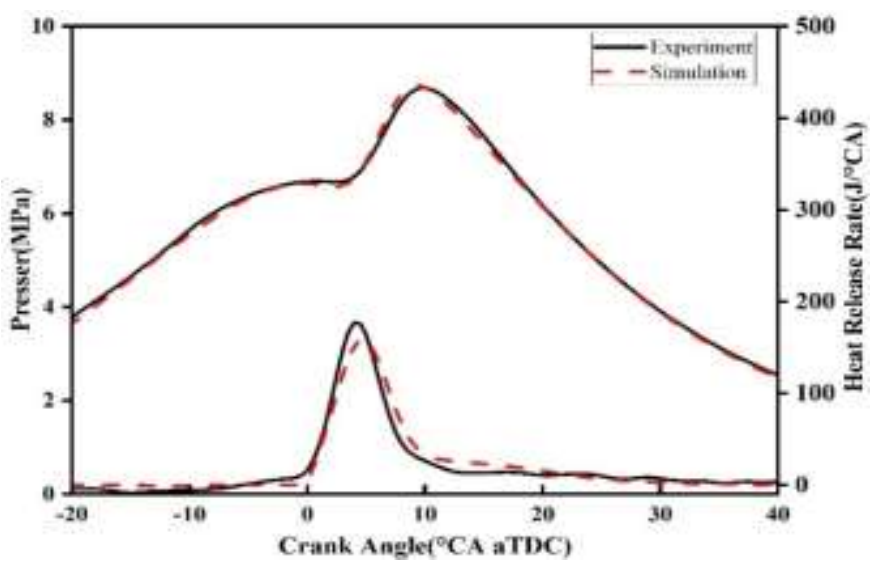

Fig.2: The comparison of cylinder pressure heat release rate between numerical simulation and test

\section{RESULTS AND DISCUSSION}

In this paper, the effect of the pre-injection ratio on the combustion and emission performance of the engine is studied under the basic conditions of 1500r/min engine speed, $40 \%$ internal EGR, secondary injection time of $-20^{\circ} \mathrm{CA}$ aTDC and total injected fuel mass is $24 \mathrm{mg} /$ cycle. Three pre-injection moments, such as $-120 /-80 /-40^{\circ} \mathrm{CA}$ aTDC, were selected to study the influence of the pre-injection ratio on the formation, combustion and emission characteristics of the gas mixture in the GCI engine under low load condition.

\subsection{Effects of pre-injection ratio on combustion characteristics of GCI on low load condition: Fig.3} shows the change of the cylinder pressure and heat release rate with the ratio of the pre-injection mass at the time of the pre-injection at $-120 /-80 /-40^{\circ} \mathrm{CA}$ aTDC. By comparison, with the increase in the ratio of the pre-injection, the peak cylinder pressure presents a trend of first rising and then falling, and the peak pressure is gradually delayed corresponding to the crankshaft angle. When the pre-injection time is -120/$80^{\circ} \mathrm{CA}$ aTDC, it can be found that the change in cylinder pressure and heat release rate is small when the change from a single injection to double injections is small. This is because the initial fuel injection is less, and the combustion is closer to a single injection. With the increase of the ratio of the pre-injection, the cylinder pressure and heat release rate are gradually delayed backward, and the phenomenon is more obvious as the pre-injection is forward.

The analysis shows that when the pre-injection is earlier than $-80^{\circ} \mathrm{CA}$ aTDC, it is mainly the increase of the ratio of the pre-injection, and there is sufficient time for mixing to form a relatively uniform mixture. In addition, the decrease of the second injection mass weakens the stratification effect on the fuel. When the pre-injection time is $-40^{\circ} \mathrm{CA}$ aTDC, by comparing the cylinder pressure and heat release rate, it can be found that with the delay of the pre-injection time, the cylinder pressure and heat release rate curves are advanced, and the combustion heat release is relatively concentrated. This is mainly due to the small time 
interval between the double injections, and the stratified effect of the formed mixture is more obvious. Under the action of the local high temperature region, the combustion is earlier.

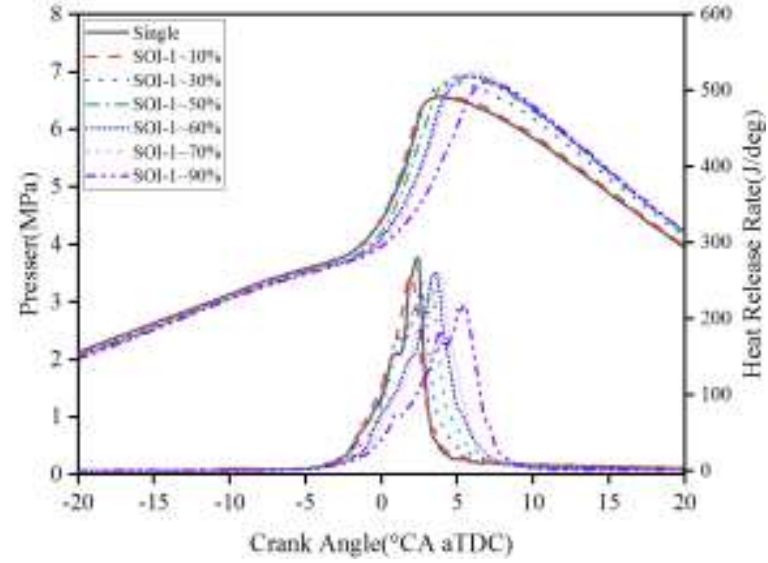

(a). $-120^{\circ} \mathrm{CA}$ aTDC

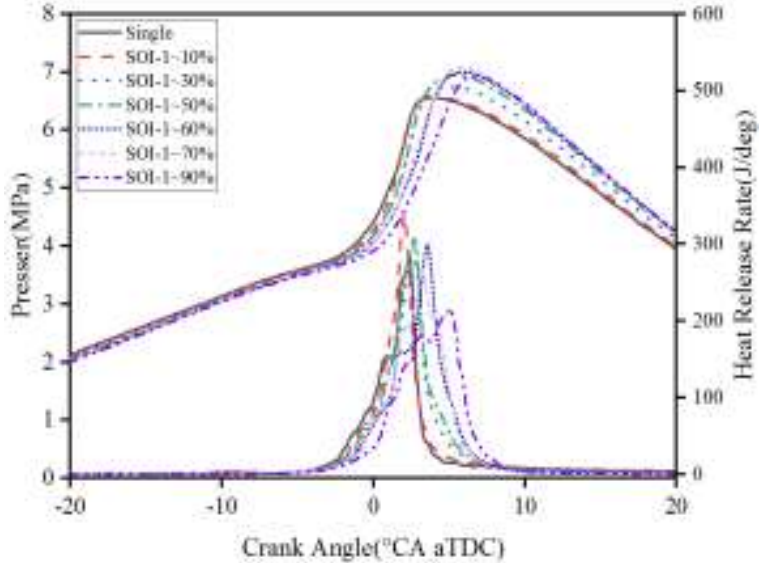

(b). $-80^{\circ} \mathrm{CA}$ aTDC

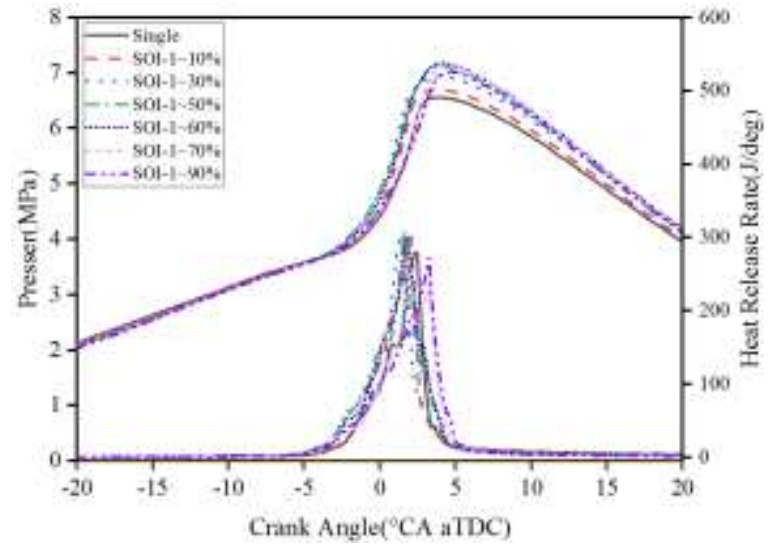

(c). $-40^{\circ} \mathrm{CA}$ aTDC

Fig.3: Variation of in-cylinder pressure and heat release rate with fuel injection ratio at different preinjection times

Fig.4 shows the variation of combustion efficiency with the injection ratio in cylinder at different preinjection times, and the combustion efficiency of single injection is only $92.94 \%$. Through comparison, it can be found that the introduction of double injection strategy can effectively improve the combustion of an internal combustion engine. With the increase of the pre-injection ratio, the combustion efficiency corresponding to the three different injection times increases first and then decreases, but the combustion efficiency is always better than that of the single injection strategy. This is because the introduction of the pre-injection changes the distribution of the mixture in the cylinder, and the reasons and effects of different injection ratios are also different. Specifically, when the initial injection ratio is less than $50 \%$, the improvement effect of the pre-injection is relatively superior. This is because the two injection times are relatively close. The time of the pre-injection of fuel and air mixing becomes shorter before the start of 
combustion, and the oil and gas mixture stratification formed in the cylinder is better, which is more suitable for combustion. Specifically, when the initial injection ratio is less than $50 \%$, the improvement effect of the pre-injection is relatively good. This is because the two injection times are relatively close. The time of the pre-injection of fuel and air mixing becomes shorter before the start of combustion, and the oil and gas mixture stratification formed in the cylinder is better, which is more suitable for combustion.

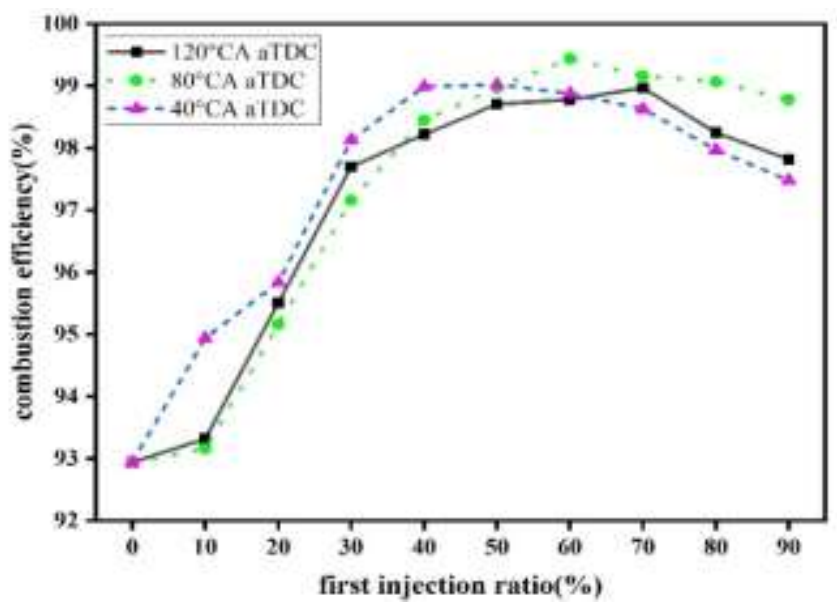

Fig.4: Variation of combustion efficiency with the pre-injection ratio at different pre-injection times

Fig.5 shows the variation of the indicated thermal efficiency with the pre-injection ratio at different preinjection times. It can be found that when the pre-injection time is- $40{ }^{\circ} \mathrm{CA}$ aTDC, the indicated thermal efficiency increases first and then decreases with the increase of the pre-injection ratio, and reaches the highest value when the pre-injection ratio is about $50 \%$.

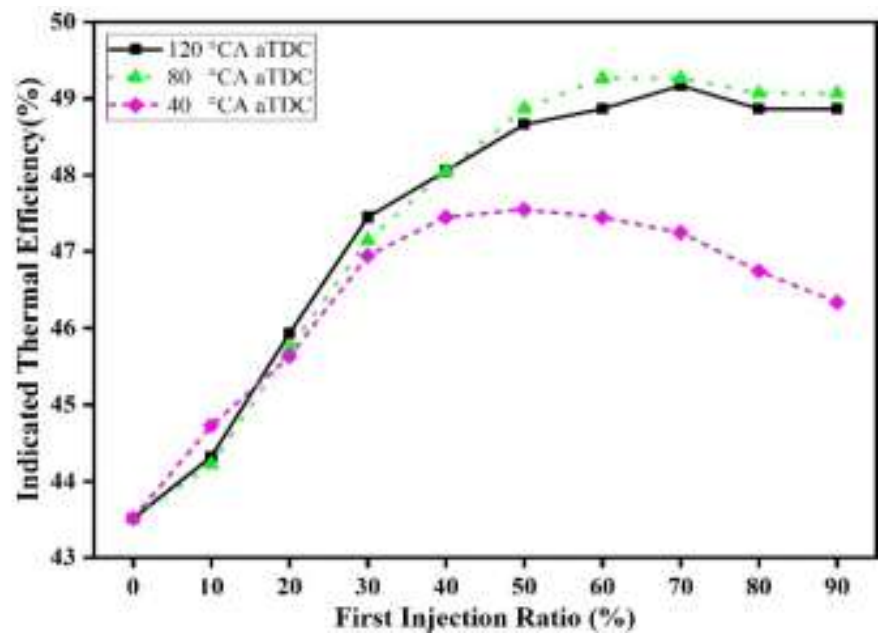

Fig.5: Variation of indicated thermal efficiency with the pre-injection ratio at different pre-injection times

As shown in Fig.6(a), the analysis shows that before $50 \%$, it can be seen that due to the relatively close two injections, the area with a relatively dense mixture in the cylinder gradually increases, which is more prone to the generation and propagation of flame, indicating that the thermal efficiency increases. Compared with the condition of the pre-injection of $-40^{\circ} \mathrm{CA}$ aTDC, the two early injections of $-120 /-$ 
$80^{\circ} \mathrm{CA}$ aTDC showed an overall upward trend and reached the highest value at about $60 \%$. The indicated thermal efficiency increased by about $5.5 \%$ from single injection to the highest. When the pre-injection ratio continued to increase, the indicated thermal efficiency decreased slightly but changed little. It can be seen that when the pre-injection time is $-80 /-120^{\circ} \mathrm{CA}$ aTDC, when the pre-injection ratio is greater than 50 $\%$, the indicated thermal efficiency of $-80^{\circ} \mathrm{CA}$ aTDC is higher. The analysis shows that the distribution of CA10 equivalence ratio at the pre-injection time of $-80 /-120^{\circ} \mathrm{CA}$ aTDC in Fig.6(b) and Fig.6(c) shows that, due to the small amount of fuel injected at low load, the earlier the injection is, the more thin mixture is formed in more areas and the combustion quality becomes worse. In addition, the early injection of large amounts of fuel will also increase the amount of fuel entering the clearance area, resulting in the abnormal combustion of some fuel and the decrease of combustion quality.

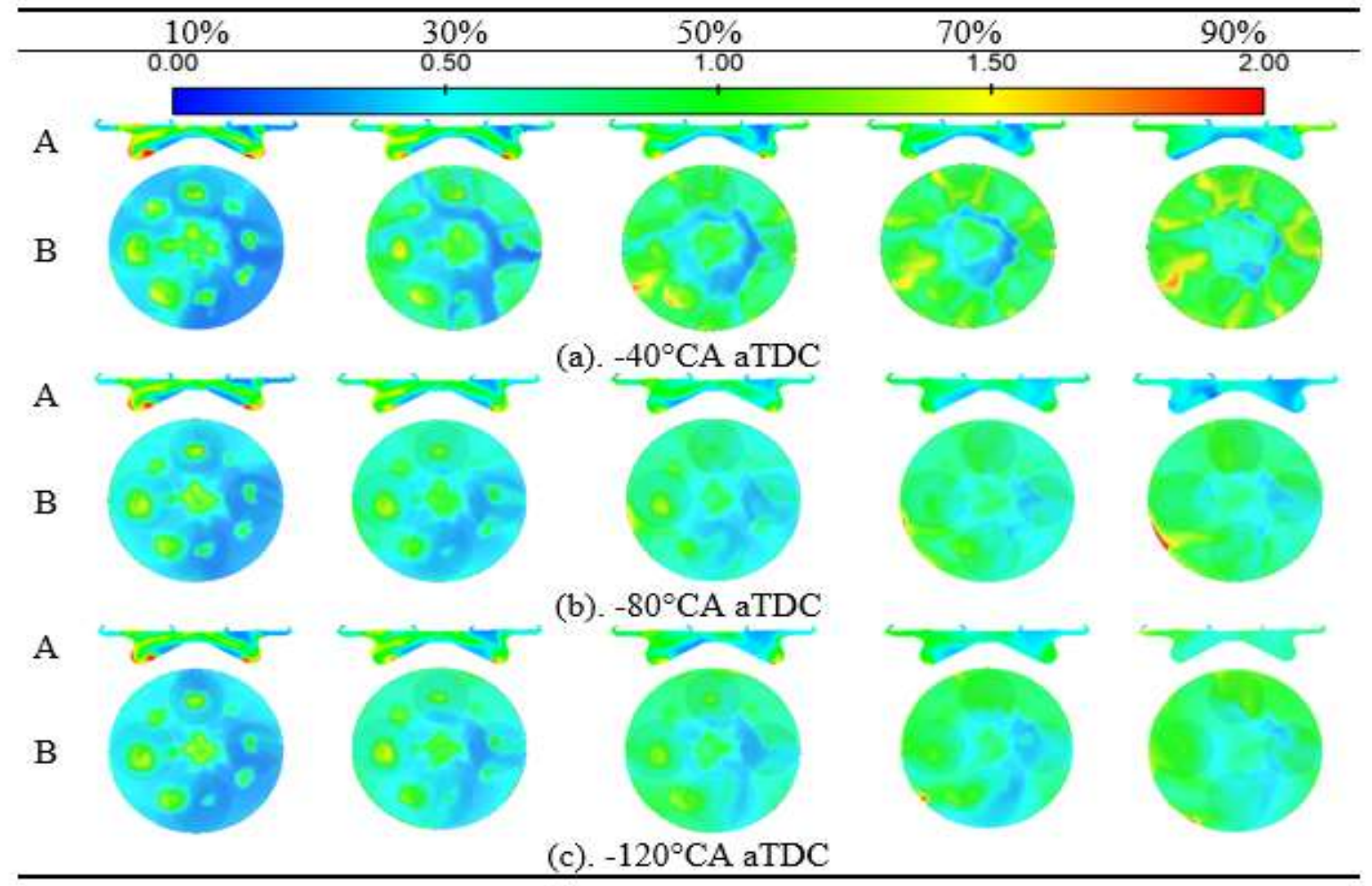

Fig.6: The CA10 equivalent ratio changes with the ratio of pre-injection when the initial injection time is $-40 /-80 /-120^{\circ} \mathrm{CA}$ aTDC

It can be seen from Fig.7 that when the pre-injection ratio increases, the combustion duration shows a significant shortening trend. Through the analysis, when the pre-injection ratio increases, the impact on the first half of the combustion is small, which is mainly in the internal EGR is certain, the temperature effect on the initial combustion stage is relatively small. It can be seen from Fig.7(a), (b), (c) that with the increase of the pre-injection ratio, CA10 and CA50 generally show a backward delay, but the change is relatively small. And it can be found that the shorter the duration, the greater the IMEP, mainly due to the shortening of the combustion duration reduces the combustion constant volume. However, with the increase of the pre-injection ratio, the combustion duration is significantly shortened both in advance injection and late injection, and the effect on the combustion duration is gradually reduced with the 
increase of the pre-injection ratio. Therefore, the introduction of the pre-injection mainly affects the latter half of the cylinder combustion (CA50-CA90).

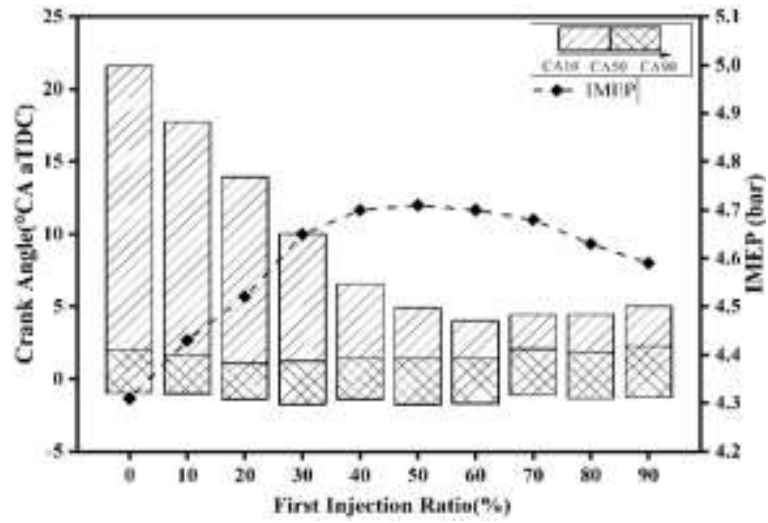

(a). $-120^{\circ} \mathrm{CA}$ aTDC

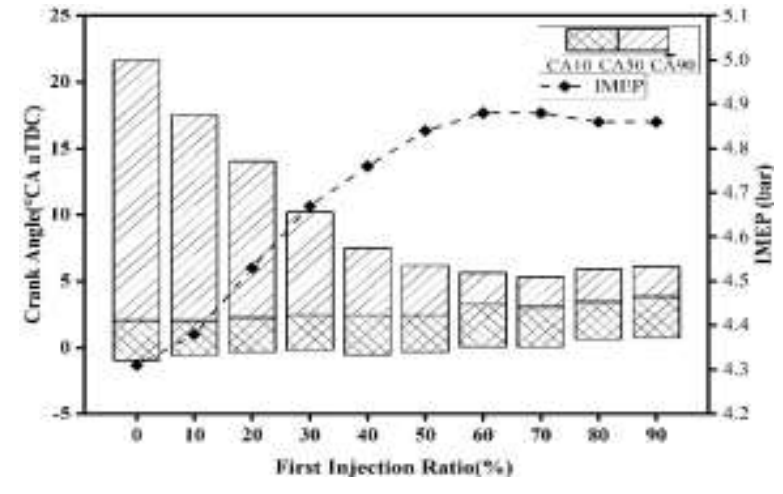

(b). $-80^{\circ} \mathrm{CA}$ aTDC

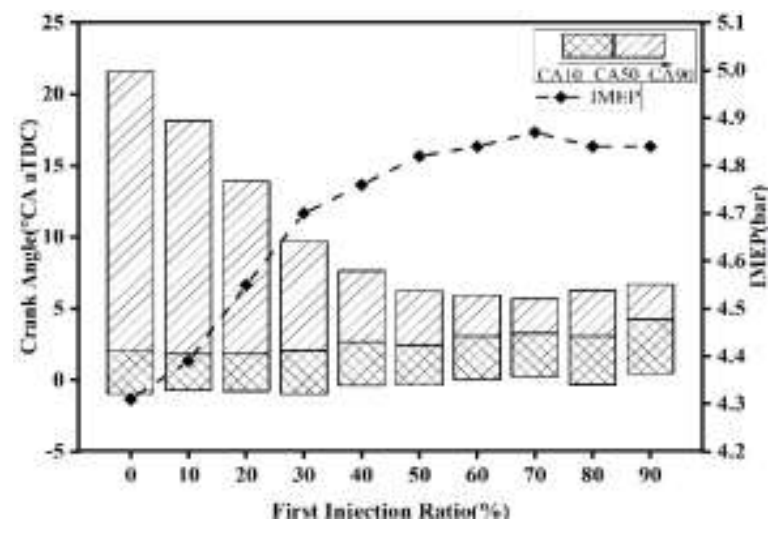

(c). $-40^{\circ} \mathrm{CA}$ aTDC

Fig.7: Variation of IMEP, CA10, CA50 and CA90 with injection ratio at different initial injection times

3.2 Effects of pre-injection ratio on combustion characteristics of GCI on low load condition: Fig.8 and Fig.9 show the variation trend of $\mathrm{HC}$ and $\mathrm{CO}$ with the pre-injection ratio at different pre-injection times. It can be found that with the increase of the pre-injection ratio, $\mathrm{HC}$ and $\mathrm{CO}$ emissions generally show a trend of first decrease and then increase. When the pre-injection ratio is less than $20 \%$, the HC emission is less late. When the pre-injection time is- $120 /-80^{\circ} \mathrm{CA}$ aTDC, the $\mathrm{HC}$ emission is significantly increased when the pre-injection ratio is $10 \%$. This is mainly due to the early pre-injection, resulting in more fuel entering the gap area, resulting in higher $\mathrm{HC}$ emission than single injection. However, when the ratio of the pre-injection exceeds $30 \%$, it can be found that the $\mathrm{HC}$ emission of the earlier pre-injection is less than that of the injection at $-40^{\circ} \mathrm{CA}$ aTDC. This is mainly due to the uneven distribution of the mixture in the cylinder caused by the late pre-injection. While the area of the local excessive concentration area increases, the separation area of the fuel distribution becomes more obvious. The increase of the too thin area has a negative effect on the flame propagation and combustion, resulting in more $\mathrm{HC}$ and $\mathrm{CO}$ emissions. For $\mathrm{CO}$, when the pre-injection amount is $10 \%$, unlike $\mathrm{HC}$ emission, $\mathrm{CO}$ emission is lower than that of single injection. This is because on the one hand, $\mathrm{HC}$ emission increases and is located in the oxygen-thin area, which cannot be further oxidized to CO. 


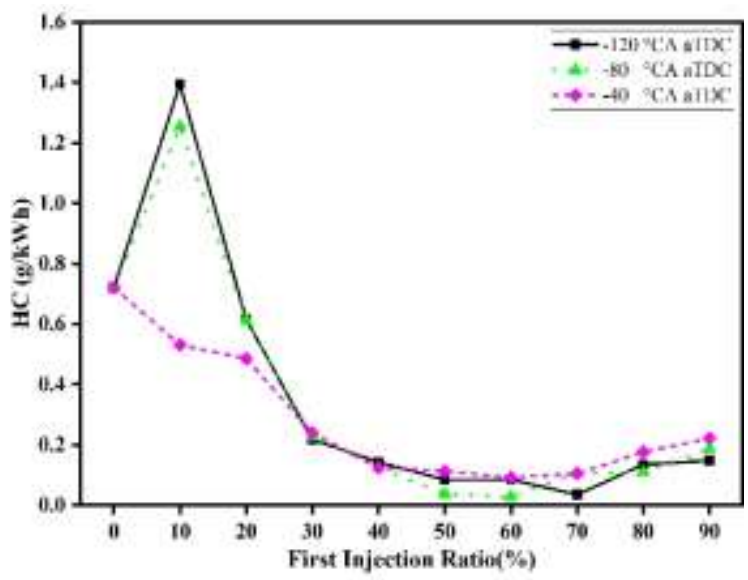

Fig.8: Influence of different initial injection time and injection ratio on $\mathrm{HC}$ emission

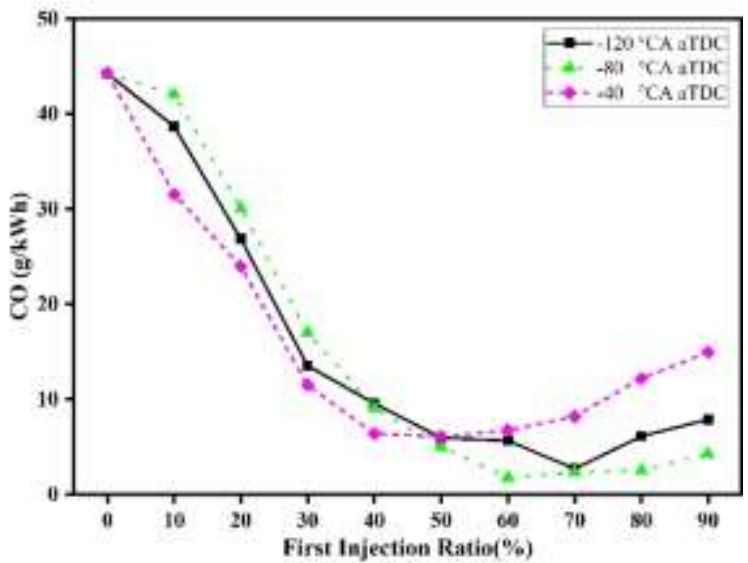

Fig.9: Influence of different initial injection time and injection ratio on $\mathrm{CO}$ emission

$\mathrm{NO}_{\mathrm{x}}$ emission is mainly determined by the mixture concentration in the cylinder, combustion temperature and high temperature duration. Fig.10 shows the variation curve of $\mathrm{NO}_{\mathrm{X}}$ emission at different preinjection time. It can be seen that the $\mathrm{NO}_{\mathrm{X}}$ emission at different pre-injection time increases first and then decreases with the increase of the pre-injection ratio, and reaches the highest value when the pre-injection ratio is about $30 \%$, and then gradually decreases.

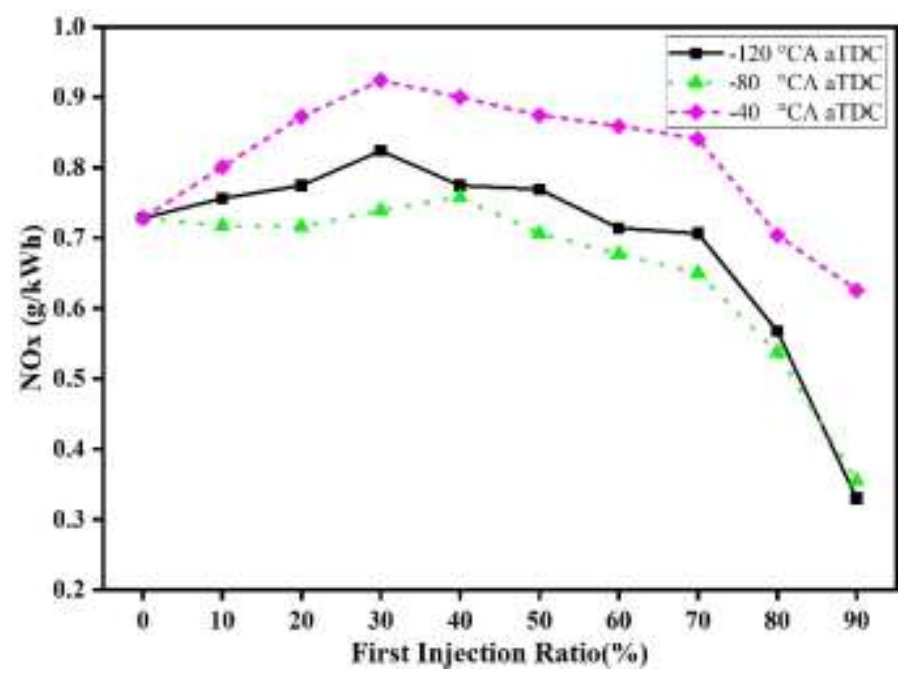

Fig.10: Influence of different initial injection time and injection ratio on NOx emission

Fig.11 and Fig.12 respectively show the temperature field distribution at the cross sections B and D when the pre-injection time is $-40^{\circ} \mathrm{CA}$ aTDC. For the pre-injection closer to the front, when the injection ratio is less than $30 \%$, because most of the fuel is injected to the bottom of the piston bowl, under the condition of high temperature and oxygen enrichment, the formation of $\mathrm{NO}_{\mathrm{X}}$ is significantly increased. When the pre-injection ratio increased to $70 \%$, the $\mathrm{NO}_{\mathrm{X}}$ emission decreased. 


\begin{tabular}{|c|c|c|c|c|c|}
\hline & $0^{\circ} \mathrm{CA}$ aTDC & & & $10^{\circ} \mathrm{CA}$ aTDC & $15^{\circ} \mathrm{CA}$ aTDC \\
\hline & 800 & 1225 & $\begin{array}{l}\text { temp } \\
1650\end{array}$ & 2075 & 2500 \\
\hline $30 \%$ & & & & & \\
\hline $90 \%$ & & & & & \\
\hline
\end{tabular}

Fig.11: Influence of fuel injection ratio on combustion temperature at section B

\begin{tabular}{|c|c|c|c|c|c|}
\hline & $0^{\circ} \mathrm{CA}$ aTDC & & & $10^{\circ} \mathrm{CA}$ aTDC & $15^{\circ} \mathrm{CA}$ aTDC \\
\hline & 800 & 1225 & $\begin{array}{l}\text { temp } \\
1650\end{array}$ & 2075 & 2500 \\
\hline $30 \%$ & & & & & \\
\hline $90 \%$ & & & & & \\
\hline
\end{tabular}

Fig.12: Influence on temperature at cross section D

This is because, with the increase of the pre-injection ratio, the main combustion area shifted from the bottom of the piston bowl to the top of the piston. Due to the high concentration of the mixture formed in this area and the low oxygen content, the NOx formation was also inhibited. In general, $\mathrm{NO}_{\mathrm{X}}$ emission is the highest when the pre-injection time is $-40^{\circ} \mathrm{CA}$ aTDC, and the lowest when the pre-injection time is $80^{\circ} \mathrm{CA}$ aTDC. The reason for this result is that when the pre-injection time is relatively backward, the fuel 
distribution is more concentrated, and the local high temperature area generated by combustion is significantly increased, resulting in a large number of $\mathrm{NO}_{\mathrm{X}}$.

However, when the pre-injection is earlier, the local high temperature area in the cylinder is significantly reduced due to the influence of the concentration distribution, so the $\mathrm{NO}_{\mathrm{X}}$ emission is low. When the preinjection ratio is $80 \%$ and $90 \%$, the $\mathrm{NO}_{\mathrm{X}}$ emission is reduced obviously. The reason is that the preinjection is more advanced and the injection ratio is more, the mixture is more uniform, and the local high temperature area caused by combustion is reduced, so the reduction is more obvious.

Fig.13 shows the effect of the pre-injection ratio on soot emissions at different pre-injection times. As an incomplete combustion product with high temperature and hypoxia, soot emission is closely related to the distribution of in-cylinder mixture and combustion temperature. From Fig.13, similar to CO emission, soot emission decreases first and then increases with the increase of the pre-injection ratio. When the preinjection ratio is less than $50 \%$, the pre-injection emission of $-40^{\circ} \mathrm{CA}$ aTDC is less than that of earlier injection due to the better combustion condition. However, when the pre-injection ratio is more than 50\%, the earlier injection is more obvious than that of $-40^{\circ} \mathrm{CA}$ aTDC. The main reason is that the late injection increases the local over-concentrated area at the top of the piston, and most of the fuel is in a high temperature and anoxic environment, resulting in a significant increase in soot emissions. The early injection makes the fuel mix longer, more uniform, and less local over-concentrated area, so the soot emissions are less.

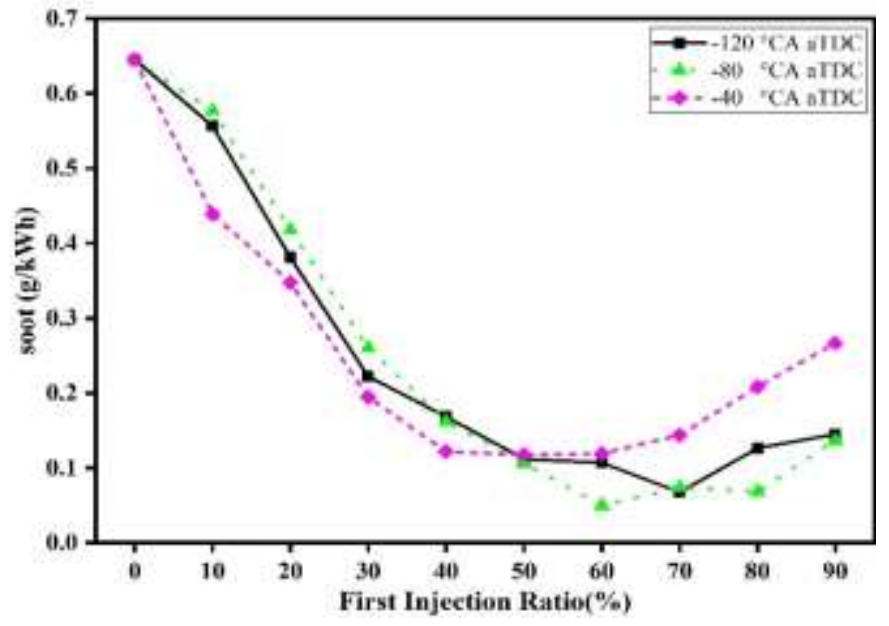

Fig.13: Influence of different initial injection time and pre-injection ratio on soot emission

\section{CONCLUSION}

In this paper, the combustion and emission characteristics of GCI under low load conditions are simulated by studying and analyzing the secondary injection strategy on the single cylinder compression ignition engine model. The results show that:

1. Compared with the single injection strategy, the double injections strategy can significantly improve the combustion and emission performance of GCI under low load condition. The combustion efficiency and indicated thermal efficiency increase significantly, and the NOx and soot emissions also decrease. 
2. With the increase of the pre-injection fuel ratio, the combustion efficiency and the indicated thermal efficiency of the three injection times increase first and then decrease, and the optimal pre-injection ratio increases gradually with the advance of the pre-injection time.

3. The pre-injection ratio has little effect on CA10 time, but the duration of combustion was significantly shortened and mainly affect the duration of the second half of combustion. At this time, IMEP has a high correlation with the duration of the second half of combustion.

\section{REFERENCES}

1. L.Fridstrom, From Innovation to Penetration: Calculating the Energy Transition Time Lag for Motor Vehicles[J]. Energy Policy, 2017, 108: 487-502.

2. M. Yao, H. Liu, Review and Prospect of the Combustion Technology of Homogeneous Charge Compression Ignition and Low Temperature Combustion[J]. Chinese Journal of Automotive Engineering, 2012, 2(2): 79-90.

3. Y. Zheng, Q. Zhang, Overview of Gasoline Engine HCCI Technology Route[J]. Internal Combustion Engine \& Parts, 2019, (16): 62-64.

4. S. Pandey, S. Bhurat, V. Chintala, Combustion and Emissions Behaviour Assessment of a Partially Premixed Charge Compression Ignition (PCCI) Engine with Diesel and Fumigated Ethanol[J]. Energy Procedia, 2019, 160: 590-596.

5. L. Tong, H. Wang, Z. Zheng et al. Experimental Study of RCCI Combustion and Load Extension in a Compression Ignition Engine Fueled with Gasoline and PODE[J]. Fuel, 2016, 181: 878-886.

6. M. Sellnau, J. Sinnamon, K. Hoyer, et al. Full-Time Gasoline Direct-Injection Compression Ignition (GDCI) for High Efficiency and Low NOx and PM[C]. SAE Technical Paper 2012-010384, 2012.

7. B. Yang, M. Yao, W.Cheng, et al. Experimental and Numerical Study on Different Dual-Fuel Combustion Modes Fuelled with Gasoline and Diesel[J]. Applied Energy, 2014, 113: 722-733.

8. W.Sun, J. Du, L. Guo, et al. The Effects of Gasoline/diesel Blend Fuels on the Combustion and Ultra-fine Particulate Emission of a Compression Ignition Engine[J]. Automotive Engineering, 2015, 37(10): 1117-1122.

9. M.Yao, S. Ma, L. Tong, et al. An Experimental on the Effects of Combustion Parameters on HPCC Combustion Fuelled with Gasoline/Diesel Dual Fuel[J]. Transactions of Csice, 2012, 30(4): 289-295.

10. M.Yao, Z. Zheng, H. Liu, Progress and Recent Trends in Homogeneous Charge Compression Ignition (HCCI) Engines[J]. Progress in Energy and Combustion Science, 2009, 35(5): 398-437.

11. G.Kalghatgi, P. Risberg, Advantages of Fuels with High Resistance to Auto-ignition in Lateinjection, Low-temperature, Compression Ignition Combustion[C]. SAE Technical Paper 200601-3385, 2006.

12. M.Sellnau,M. Foster, W. Moore, et al. Pathway to 50\% Brake Thermal Efficiency Using Gasoline Direct Injection Compression Ignition[C]. SAE Technical Paper 2019-01-1154, 2019. 
13. M.Sellnau, J. Sinnamon, K. Hoye, et al. Gasoline Direct Injection Compression Ignition (GDCI) Diesel-like Efficiency with Low $\mathrm{CO}_{2}$ Emissions[C]. SAE Technical Paper 2011-01-1386, 2011.

14. X. Zhang, P. Kumar, Y. Pei et al. An Experimental and Computational Investigation of Gasoline Compression Ignition Using Conventional and Higher Reactivity Gasolines in a Multi-Cylinder Heavy-Duty Diesel Engine[C]. SAE Technical Paper 2018-01-0226, 2018.

15. R.Cracknell, J. Ariztegui, T. Dubois, et al. Modelling a Gasoline Compression Ignition (GCI) Engine Concept[C]. SAE Technical Paper 2014-01-1305, 2014.

16. H. Fang, Q. Wang, Z.He, et al. Study on Spray and Combustion Characteristics of Pilot-Main Injection Under Two-Injection Strategy[J]. Chinese Internal Combustion Engine Engineering, 2018, 39(5): 8-13.

17. X.Liu, L. Tong, Wang $\mathrm{H}$, et al. Experimental and Modelling Investigations of the Gasoline Compression Ignition Combustion in Diesel Engine[C]. SAE Technical Paper 2017-01-0741, 2017.

18. Z.Zheng, H. Zha,H. Liu, et al. Effects of Split Injection Parameters and EGR on Combustion and Emissions of GCI[J]. Journal of Combustion Science and Technology, 2018, 24(4): 307-314.

\section{Corresponding author: Binbin Yang}

School of Transportation and Vehicle Engineering, Shandong University of

Technology, 12 Zhangzhou Road, Zhangdian, Zibo 255049, China

email: yangbinbin@sdut.edu.cn

Online date of publication: 31.03.2021 